\title{
Debts, Oligarchies, and Holisms: Deconstructing the Fallacy of Composition
}

\section{MAURice A. FinOCCHIARo}

\author{
Department of Philosophy \\ University of Nevada, Las Vegas \\ 4505 Maryland Parkway Box 455028 \\ Las Vegas, NV 89154-5028 \\ U.S.A. \\ maurice.finocchiaro@unlv.edu
}

\begin{abstract}
This is a critical appreciation of Govier's 2006 ISSA keynote address on the fallacy of composition, and of economists' writings on this fallacy in economics. I argue that the "fallacy of composition" is a problematical concept, because it does not denote a distinctive kind of argument but rather a plurality, and does not constitute a distinctive kind of error, but rather reduces to oversimplification in arguing from micro to macro. Finally, I propose further testing of this claim based on examples involving public vs. private debt in economics; oligarchic tendencies in politics, and the emergence of societal wholes in sociology.
\end{abstract}

Résumé: Il s'agit d'une appréciation critique du discours de Govier lors du congrès d'ISSA en 2006 sur le sophisme de composition, et des écrits des économistes sur cette erreur en économie. Je soutiens que le «sophisme de composition» est un concept problématique, car il ne désigne pas un type distinctif d'argument, mais plutôt une pluralité d'arguments, et ne constitue pas un type distinctif d'erreur, mais plutôt réduit les raisonnements du micro au macro à une simplification excessive. Enfin, je propose d'effectuer d'autres essais de cette affirmation en m'appuyant sur des exemples concernant la dette publique vs privée en économie; des tendances oligarchiques dans la politique et l'émergence d'ensembles sociétaux en sociologie.

Keywords: Trudy Govier, Henry Hazlitt, Paul Samuelson, argument from composition, economic fallacies, fallacy of composition, holism, oligarchy, oversimplification, public vs. private debt

(C) Maurice Finocchiaro. Informal Logic, Vol. 33, No. 2 (2013), pp. 143-174. 


\section{Maurice Finocchiaro}

\section{Govier on the fallacy of composition}

In 2006, Trudy Govier delivered a keynote address to the sixth conference of the International Society for the Study of Argumentation (Govier 2007; 2009). Its revealing title was "Duets, Cartoons, and Tragedies: Struggles with the Fallacy of Composition." In it, she insightfully discusses a number of problems stemming from the following fundamental fact: that "we apply to groups the intentional language of emotions, attitudes, and beliefs. Such language is paradigmatically individual in application and yet we apply it to groups of all sizes - small, medium, large and very large - and of varying degrees and kinds of organization" (Govier 2009, p. 91). ${ }^{1}$

In elaborating her account, Govier follows and exhibits an approach or orientation which is fruitful and deserves greater diffusion, and which I would characterize as judicious. I define judiciousness, or balanced judgment, as the avoidance of one-sidedness and of extremes, and I certainly endorse such an approach. ${ }^{2}$

In fact, to begin with, Govier rejects "the supposition that, with respect to intentional language, group attributions are problematical whereas individual attributions are not" (p. 92); this would amount to an undesirable "dichotomous contrast between individual and group" (p. 92). Furthermore, she rejects both of two extreme positions: that "all intentional language, as applied to groups, is based on error ... [and] should be banned" (p. 94); and that "intentional language as applied to groups must be legitimate

\footnotetext{
${ }^{1}$ Subsequent references to Govier 2009 will be given by mentioning just the page number(s).

2 I have argued before that judiciousness is an important element of Galileo's scientific approach, and of the scientific method in general (Finocchiaro 1980, pp. $145-166 ; 2005$, pp. $361-430 ; 2010$, pp. 121-134); that it is the plausible kernel of Hegelian dialectic, and a valuable and viable approach in the social sciences and humanistic disciplines (Finocchiaro 1988, pp. 228-230; 2005, pp. 207230); and that a judicious-minded approach is a fruitful orientation to follow in logic and argumentation theory (Finocchiaro 2005, pp. 21-108; 2013, pp. 4-17).
}

(C) Maurice Finocchiaro. Informal Logic, Vol. 33, No. 2 (2013), pp. 143-174. 
... it passes the only realistic and sensible test of legitimacynamely actual use" (p. 94).

Govier's formulation of the problem and description of the project provide another good example of judiciousness. To see this, let us begin with Govier's stipulation of the nominal definition to "call the application of intentional language to groups the compositional phenomenon" (p. 92), and the attribution of an intentional predicate to a group a compositional attribution. Then the problem is this: "compositional attributions pose questions, especially when claims about group actions and attitudes are based on evidence about individuals. Real issues arise. The challenge is to acknowledge the gap and the problem, and find ways in which the gap can be bridged" (p. 95).

In a large and important class of cases, "the gap ... can be bridged insofar as group structures and relationships provide contexts for people to think together and act on the basis of their joint deliberations. We can understand how the deliberations and actions of an interactive group provide grounds for attributing to it attitudes and beliefs: the individuals are not considered purely individualistically when they think and act together; thus they stand in relationships and constitute a group" (p. 103). This happens when groups have some kind of elected executive that represents the members, and the members can explicitly or tacitly express their consent or disapproval.

Besides following such a sound judicious approach to the compositional phenomenon and compositional attribution, Govier's account deserves credit for practicing a realistic approach, in the sense that she discusses real or realistic examples and materials. That is, her analysis is meant to shed light on actual practical problems in all their complexity, as contrasted to artificial, abstract, or invented examples in an oversimplified context. And such realism is not an accidental feature of Govier's 2006 ISSA address, for she has regularly practiced it in other works and reflectively advocated it on various occasions (Govier 1987; 1999; 2000, 289-290). I also

(C) Maurice Finocchiaro. Informal Logic, Vol. 33, No. 2 (2013), pp. 143-174. 


\section{Maurice Finocchiaro}

advocate such a methodological approach, as do other scholars, although it goes under various labels, such as empirical, historical, pragmatic, and naturalized. ${ }^{3}$

For example, Govier analyzes the case of the newspaper cartoons about the prophet Mohammed, which were published in Denmark in 2006 and elicited widespread protest by Muslims, especially in Islamic countries. Here, she valiantly tries to sort out who is attributing what violent attitudes to such groups and wholes as Denmark, the West, and Islam, on the basis of facts about the behavior and attitudes of individual Danish journalists and cartoonists and individual Islamic terrorists and protesters. The importance and relevance of such analytical efforts were underscored just recently, in the autumn of 2012, with the eruption in Muslim countries of similar protests elicited by the private production in the United States of an amateurish video about the prophet Mohammed.

Govier also discusses certain aspects of the activities of the South African Truth and Reconciliation Commission (pp. 99-100). She examines ways of bridging the gap between the reconciliation of individuals with each other, however numerous, and national reconciliation between races in the society at large. Govier also mentions briefly the much-discussed "tragedy of the commons," in which individuals can benefit, and do benefit, by exploiting a common good, but only as long as the whole group does not undertake such an exploitation; for example, one farmer may be able to make a living by grazing his cattle on public land, but if all farmers graze their cattle on the same public land there may not be enough pasture for all. And she also mentions briefly the problem of world hunger, and whether it can be effectively solved or alleviated by

\footnotetext{
${ }^{3}$ Cf. Barth, Vandormael, and Vandamme 1992; Finocchiaro (2005, pp. 21-91, 128-147; 2013, pp. 4-17); Fisher 2004; Johnson 2000; Woods 2013. The last mentioned work strikes me as being a novel departure from some of Woods's earlier work (such as Woods and Walton 1977a; 1977b), although undoubtedly there is some continuity of evolution and development between the two.
}

(C) Maurice Finocchiaro. Informal Logic, Vol. 33, No. 2 (2013), pp. 143-174. 
means of actions and attitudes analogous to those whereby a family deals with the hunger of some of its members. On all such examples, Govier has insightful things to say and to convey on several levels: substantive social commentary, methodological illustration of the judicious and realistic approaches, and theoretical analysis of the compositional phenomenon and compositional attributes.

Let us now ask what any of this has got to do with logic and argumentation theory in general, and the "fallacy of composition" in particular. For, after all, Govier's key aim in her 2006 address is "to relate this problem more specifically to issues about argument and argumentation" (p. 95).

We may begin by focusing on the common nominal definition which Govier adopts: "what I have in mind here is the Fallacy of Composition, in which we mistakenly infer conclusions about wholes or groups from premises about parts or individuals" (p. 92). Let me note, however, that in this passage as well as in the rest of her essay, she always spells the term 'fallacy of composition' with initial capital letters. This orthographical minutia turns out to be very revealing, for, as we shall see latter, Govier's account embodies a questionable hypostatization of the "fallacy of composition."

On the other hand, here Govier wisely ignores "the fallacy of arguing from premises in which a term is used distributively to a conclusion in which it is used collectively" (Webster's Third New International Dictionary 1976, p. 818), which many authors mention as a special case of the fallacy of composition. For example, Copi (1968, p. 81) illustrates this notion with the example: "because a bus uses more gasoline than an automobile, therefore all buses use more gasoline than all automobiles." And this notion has the historical pedigree of being traceable to the Port Royal Logic (Arnauld and Nicole 1996, pp. 199-200). However, the amalgamation of this notion with the compositional phenomenon of which Govier speaks would only introduce confusion into the discussion, perhaps even committing a fallacy of equivocation. Thus, Govier is right to say nothing about it. But this is not to deny that it would be

(c) Maurice Finocchiaro. Informal Logic, Vol. 33, No. 2 (2013), pp. 143-174. 


\section{Maurice Finocchiaro}

useful to have a historical account of the various definitions of the fallacy of composition, or of its various elements. In this regard, Woods's (2012) general account of the history of fallacies is useful, but only a start.

We may also agree that the compositional phenomenon, the problem of compositional attribution, and Govier's real examples have something to do with the fallacy of composition so defined; this seems obvious at an intuitive level and from the point of view of over-all judgment. To have seen such a connection and to have attempted to articulate it is a very valuable aspect of Govier's essay. This value may be better appreciated if one reads other works dealing with the same topic (i.e., the relationship between claims about individuals and claims about groups), which are full of useful information and subtle and insightful analyses, but do not as much as mention the fallacy of composition. ${ }^{4}$ But the challenge is to articulate clearly what precisely the connection is between such realistic material and cognitive phenomena on the one hand, and logic, argumentation theory, and the fallacy of composition on the other.

For example, is it the case that "the Fallacy of Composition is genuinely a fallacy, and an important one" (p. 92)? And that "the existence and understanding of this gap [in compositional attributions] underpin the tradition of the Fallacy of Composition ... this fallacy is genuine and important" (p. 102)? I am not sure that this is the case, or that Govier succeeds in showing that it is. On the contrary, what she herself says and argues shows almost the opposite.

In fact, let us be clear about what her project of "gapbridging" is and what it accomplishes. She is correctly claiming that there is indeed a gap between the intentional predicates attributed to individuals and to groups, but that the gap can sometimes be bridged; the real challenge is to determine when the gap

\footnotetext{
4 The most outstanding example of such non-logical and non-argumenttheoretical approach is Jones $(2003 ; 2010)$. However, the materials and analyses in these works could be exploited and adapted from the point of view of the fallacy of composition (as well as the reverse fallacy of division).
}

(C) Maurice Finocchiaro. Informal Logic, Vol. 33, No. 2 (2013), pp. 143-174. 
can, and when it cannot be bridged, and what are the factors and conditions that allow the gap to be bridged. What this means is that compositional attributions are sometimes correctly made on the basis of the behavior and characteristics of individuals. Thus, in such cases, no fallacy of composition is being committed.

Now, it would be a misconception to describe this situation by saying that the fallacy of composition is not always fallacious, for this claim would be tantamount to a self-contradiction: that it is not always mistaken, erroneous, or incorrect to "mistakenly infer conclusions about wholes or groups from premises about parts or individuals" (p. 92). However, such a self-contradiction is easily avoided, with resources that are contained in Govier's own essay.

That is, before defining the fallacy of composition we should define what might be called the argument from composition. ${ }^{5}$ In the present context we need not decide whether this term should be preferred to several others that easily come to mind: compositional argument, argument of composition, and argument by composition. Govier herself comes close to formulating such a definition in the concluding section, where she speaks of arguments "when premises are about individuals and conclusions are about groups" (p. 102). Similarly, after presenting the compositional phenomenon and the problem of compositional attribution in general, she starts to elaborate a connection with logic or argumentation by focusing on "reasoning from premises about parts to a conclusion about a whole" (p. 95). But the notion can also be defined by appropriately modifying the definition of this fallacy which she adapts from traditional accounts. Thus, in the definition I quoted (five paragraphs) above, we can drop the word "mistakenly," and then we get that a compositional argument is one "in which we ... infer conclusions about wholes or groups from premises about parts or individuals" (p. 92). Such a notion of compositional argument is essentially the

\footnotetext{
${ }^{5}$ Walton, Reed, and Maccagno (2008, p. 113) also take such a step; but then they seem to stop there, in the sense that what they go on to say regarding the critical evaluation of such arguments is unhelpful.
}

(C) Maurice Finocchiaro. Informal Logic, Vol. 33, No. 2 (2013), pp. 143-174. 


\section{Maurice Finocchiaro}

logical or argument-theoretical translation or analogue of the compositional phenomenon and of compositional attribution.

Once we have such a notion of compositional argument, then we could utilize Govier's account of gap bridging or filling to claim the following. If and insofar as the gap between premises and conclusion in a compositional argument has been bridged, such a compositional argument is cogent or correct. If and to the extent that the gap has not been bridged, such a compositional argument is erroneous or mistaken. We could then try to define a fallacy of composition as a compositional argument that is erroneous. At least this would avoid the misconception or self-contradiction mentioned earlier, that fallacies of composition are sometimes cogent arguments.

So far, such a modified definition of fallacy of composition would be satisfying only two of the necessary conditions for something (a cognitive practice or sequence of thoughts) to be a fallacy: that it be argumentation or reasoning, and that it be erroneous or mistaken. However, the traditional concept of fallacy includes other necessary conditions: the fallacy must be a kind of argument or manner of reasoning; it must be commonly or frequently committed; and it must have the appearance to be correct, i.e., must be deceptive (although not in the sense of being accompanied by an intention to mislead, but rather in the sense of being perceived as correct by oneself and others). In short, the traditional concept of fallacy amounts to this: a fallacy is a (1) common (2) kind of (3) argument that (4) seems correct but (5) is not. ${ }^{6}$

6 This claim, together with my critique below, has been inspired by Woods
(2013), who argues in detail that the traditional concept of fallacy has these fea-
tures, and that at least fourteen of the traditional list of eighteen fallacies do not
really instantiate the traditional concept. Needless to say, I am not attributing to
Woods the critical argument I develop here, but the inspirational connection and
subjective debt on my part is present. Readers acquainted with Woods (2013)
should not be surprised at this, given that they can easily see this attitude of mine
to be a kind of mirror image of the one displayed therein by Woods towards Fi-

(C) Maurice Finocchiaro. Informal Logic, Vol. 33, No. 2 (2013), pp. 143-174. 
The historical pedigree of this concept could be documented from sources such as the following, ${ }^{7}$ where I have inserted numbers labeling various clauses to make them correspond to my formulation just given. In Elements of Logic, Richard Whately (1826, p. 131) states that "by a Fallacy is commonly understood 'any [5] unsound [2] mode of [3] reasoning, which [4] appears to demand our conviction, and to be decisive of the question at hand, when in fairness [5] it is not'." Furthermore, in "A History of the Fallacies in Western Logic," John Woods (2012, p. 514) states that "roughly speaking, the traditional concept of fallacy is that of a [5] mistake of [3] reasoning which people [2] in general tend to commit with a [1] notable frequency and which, even after successful diagnosis, are [4] subject to this same inclination to commit." And Govier herself agrees that "by definition, a fallacy is a [5] mistake in [3] reasoning, a mistake which occurs with some [1] frequency in real arguments and which is characteristically [4] deceptive" (1995, p. 172). ${ }^{8}$

Without worrying here about conditions (1) and (4), and having already discussed (3) and (5), let us focus on condition (2). When Whately speaks of a "mode" of reasoning, we may take this to refer to a manner or style of reasoning, as distinct from merely an instance or particular occurrence of reasoning. When Woods requires that a fallacy be such that thinkers "in general tend to commit" it, he may be construed as referring to a general habit or universal tendency, not to occasional occurrences or individual episodes of mistaken reasoning. When in my own formulation above I spoke of "kind," I meant it to be a natural kind, definable in terms

nocchiaro $(1981 ; 1987)$. Concerning the latter, see also Govier $(1982 ; 1987$, chapter $9 ; 1995)$.

${ }^{7}$ However, see the criticism of such a historical thesis advanced by Hansen (2002). Still, I do not think his criticism undermines my main point here, partly because the target of his criticism is a much more oversimplified concept of fallacy than the one I am advocating.

${ }^{8}$ For the last two references, see also, respectively, Woods 2013, chapter 4.6; Govier 2010, pp. 66, 85 .

(c) Maurice Finocchiaro. Informal Logic, Vol. 33, No. 2 (2013), pp. 143-174. 


\section{Maurice Finocchiaro}

of some concrete or tangible or deep-structural property, as distinct from some epiphenomenal or superficial or artificial characteristic.

In Govier's formulation quoted above, she does not explicitly include this condition. Thus, it is not absolutely clear whether or not she would accept it. But it is likely that she would, because this is suggested by her saying that fallacies are "characteristically" deceptive. This seems to mean that they are typically deceptive, and they tend to be deceptive. And such a characteristic, typical, or tendential deceptiveness could hardly subsist or happen without the argument in question being a member of a real class or natural kind.

This condition of generality is relevant and important in the present context because the fallacy of composition as defined so far, even according to the modified definition given above, is not a real type or natural kind of argument. In fact, in an analysis which is both cogent and interesting, Govier herself shows that the fallacy of composition is not an argument type. Recall that, in accordance with the modified definition, a fallacy of composition must be, and can only be, a fallacious argument from composition; and that an argument from composition is one containing reasoning from premises about the properties of parts or individuals to a conclusion about the properties of wholes or groups.

The passage containing this analysis is worth quoting in its entirety, but to be fully and immediately transparent, it is useful to recall and elaborate some aspects of the content and structure of Govier's examples. So far, I have not even mentioned the "duet" example which she briefly discusses: "John is a terrific tenor and Susan is a brilliant soprano. So a duet by John and Susan will be superb" (p. 95). Wisely and mercifully, Govier wastes no time and space on this example. Here, she is presumably echoing the example of Copi (1968, p. 80): "since every part of a certain machine is light in weight, the machine 'as a whole' is light in weight." Nevertheless, it may be worth pointing out that such arguments are de-

(C) Maurice Finocchiaro. Informal Logic, Vol. 33, No. 2 (2013), pp. 143-174. 
ductively invalid, and so if they are regarded as deductive arguments, they are incorrect.

Let us now consider the example of the Danish newspaper cartoons about the prophet Mohammed and the violent Muslim demonstrations against them in Islamic countries. Govier elaborates how some key aspects of some people's thinking about this were inductive generalizations, but hasty ones; for example, some Danes have offended some Muslims, therefore Denmark (or the West) has offended Islam; or, some Muslims have committed violence against some Westerners, therefore Islam has committed violence against the West. The tragedy of the commons also has an element of hasty generalization.

The world-hunger example appears, instead, to involve analogical reasoning. The argument would be that the world community should take some action to alleviate world hunger, because in a family no one would prepare dinner but exclude a family member from the table. Here, the whole world is being regarded as analogous to a part of it - the family.

Finally, in her analysis, to be quoted presently, Govier says that some instances of the fallacy of composition may be interpreted as inferences to the best explanation. However, she gives no explicit example of this connection, and as far as I can tell none of the examples she gives can be viewed in this manner.

With these points in mind, we are now ready to appreciate the full cogency of Govier's meta-argument:

In terms of the theory of argument, it is interesting to note that the Fallacy of Composition can appear in arguments of different types. If an argument is taken to be deductive, and the premises are about individuals while the conclusion is about a group, clearly that argument will be deductively invalid in the straightforward sense that it will be possible for the premises to be true while the conclusion is false. We may locate the Fallacy of Composition within this gap. If an argument is taken to be an analogical argument in which the

(c) Maurice Finocchiaro. Informal Logic, Vol. 33, No. 2 (2013), pp. 143-174. 


\section{Maurice Finocchiaro}

primary subject is a macro phenomenon, while the analogue is described at the micro level, the analogy will be inadequate because there are relevant differences between the analogue and the primary subject. We consider the Fallacy of Composition in considering the nature and relevance of these differences. If an argument from individual to group is taken as inductive generalization, it can be criticized as hasty; the individual cases do not give sufficient evidence about the group as a whole. If it is regarded as an inference-to-thebest-explanation, there will be doubts about whether a compositional attribution to a group does, indeed, provide the best explanation of the possession of characteristics by an individual or individuals, given that individuals within the group may differ from each other and can exert a certain degree of autonomy. (P. 96)

The upshot of these last considerations is that compositional arguments do not constitute a "kind" of argument, at least not in the sense in which this notion applies to deductions, arguments from analogy, inductive generalizations, and inferences to the best explanation. One implication of this regards the slightly revised, self-consistent notion of the fallacy of composition. That is, even if we define the "fallacy of composition" as a mistaken argument of composition, it does not seem to be a fallacy in the traditional sense, since it fails to satisfy the generality condition, number (2). In short, so defined, fallacies of composition are not really fallacies. ${ }^{9}$

\footnotetext{
${ }^{9}$ It could be objected that the main strand of my argument in this paragraph assumes that a "kind" of argument must be distinct from other "kinds," and this assumption is unwarranted because all argumentation schemes overlap. However, although it is true that some schemes overlap, not all do, and so the compositional scheme could very well be one of those that do not. Moreover, it seems to me that it would be pointless to define a kind that was not distinct from other kinds, and so a kind must be sufficiently well defined to be distinctive.

Another objection might be that what I call the generality condition (no. 2) can be satisfied in another way than the direct manner of the reasoning instan-

(C) Maurice Finocchiaro. Informal Logic, Vol. 33, No. 2 (2013), pp. 143-174.
} 
The consequences for Govier's notion of the Fallacy of Composition are perhaps even worse. Earlier we saw that the Fallacy of Composition (as defined by Govier) was not always a fallacy, since some compositional arguments were not mistaken, according to her own gap-bridging analysis. Thus, one might say that Govier's "Fallacy of Composition" is not an evaluative category, in the sense that it is not a principle or rule that would enable, or assist, us in determining whether or not a given argument or piece of reasoning is correct or erroneous. Additionally, from the last considerations, it seems that Govier's Fallacy of Composition is not an interpretive concept either, for it is not a concept whose application to a real case tells us much, if anything, about the type, kind, or manner of reasoning involved. It follows that it is unclear what role, if any, such a Fallacy of Composition plays in logic and argumentation theory.

In short, Govier's Fallacy of Composition is not really a fallacy, in the traditional sense. There are at least two reasons for this: the Fallacy of Composition is not always a mistake, but rather sometimes correct; and the Fallacy of Composition is not a kind of argument or manner of reasoning, but rather a mere instance of argument or reasoning.

tiating the properties that make up the definiens of the kind. This alternative might be an indirect method, along the lines of what Walton (2010) calls "paraschemes"; that is, a given instance of reasoning would be classified as belonging to the scheme of compositional argument because it is psychologically perceived as belonging to some simplified "parascheme" heuristically associated with that scheme. Here my short answer to this objection is that I find Walton's concept and application of parascheme so obscure that the project strikes me as an attempt to explain a relatively puzzling phenomenon (that fallacies appear to be better arguments than they are) in terms of things that are even more difficult to understand.

(C) Maurice Finocchiaro. Informal Logic, Vol. 33, No. 2 (2013), pp. 143-174. 


\section{Maurice Finocchiaro}

\section{The fallacy of composition in economics}

The preceding critical appreciation of Govier's account should not be regarded as the end of the story, but rather as something of a beginning - an introduction to the study of the fallacy of composition. For it would be a violation of balanced judgment to interpret the main conclusion of my critique as claiming prematurely that the fallacy of composition is a chimera of no importance or relevance to logic and argumentation theory. Moreover, the realistic approach suggests or requires that we examine more empirical material or actual examples involving compositional phenomena, attributions, and arguments. Thirdly, although, as we have seen, Govier's account suggests that the fallacy of composition be self-consistently defined as an erroneous argument of composition, and although the notion of compositional argument can be criticized as not constituting a natural kind or normal type of argument, it is proper to attempt to clarify this notion further; for example, one could try to determine whether compositional arguments, besides their nominal definitional property, have other theoretically or methodologically significant characteristics that might enable us to interpret them more deeply and evaluate them more effectively. Finally, Govier herself makes an apparently incidental remark that turns out to be very revealing and fruitful, and so I have no hesitation in crediting her for suggesting or inspiring a novel line of investigation. ${ }^{10}$ Let us then reconstruct such a novel research project.

About halfway into her essay, Govier casually mentions that "the Fallacy of Composition ... has been strikingly memorialized in a sculpture by that name at the University of Groningen. This sculpture, a lighted structure, by Trudi van Berg and Jos Steenmeijer, occupies most of a wall on the building for the Faculty of Economics" (p. 95). She cites a website, which is relatively user-

\footnotetext{
${ }^{10}$ It should also be mentioned that the title of my essay is modeled on hers, although I also adopted (mutatis mutandis) the title of Woods (1988), which may have served as her own model in the first place.
}

(C) Maurice Finocchiaro. Informal Logic, Vol. 33, No. 2 (2013), pp. 143-174. 
friendly, and where one can view an image of the sculpture. The site also contains some comments, the most relevant of which is the following: "this work ... was inspired by an economic concept. The work of John M. Keynes led to valuable insights, including the fact that macro-economy - the behaviour of aggregated variablesis very different to micro-economy, or the behaviour of individuals. The whole behaves very differently to the sum of its parts. This is known as 'the fallacy of composition'. In 1998 the Faculty of Economics celebrated its 50th anniversary ...” (http://www.rug.nl/scienceand-society/sculpture-project/sculpture1998?lang=en; consulted on July 24, 2012).

That is, this Groningen website seems to be claiming that a key achievement of Keynesian economics was to expose the fallacy of composition presumably committed in the economic thinking of common people and of previous economists. Such a judgment is very widely shared. For example, if one consults the entry "Keynes" in the Cambridge Dictionary of Philosophy (Nelson 1999), one finds an interpretation that implicitly reinforces it. Although the entry does not mention the fallacy of composition, it does attribute to Keynes a focus on the distinction between micro and macro economics, and on ways to interrelate them.

Such hints revived my memory of having taken, during my undergraduate studies, an introductory economics course taught by the famous economist Paul Samuelson, and I seemed to recollect some discussions of the fallacy of composition. This led me to consult his textbook Economics (Samuelson 1955), which is still in my possession. I was amazed, but not surprised, to discover that it is full of critical discussions of economic examples of the fallacy of composition. Here then is a goldmine of material that deserves serious attention and careful study by logicians and argumentation theorists, and I will presently undertake a preliminary examination of it. But before doing that, it is worth mentioning a number of economic-related points that attest to the general cultural relevance and awareness of the fallacy of composition in economics: after

(c) Maurice Finocchiaro. Informal Logic, Vol. 33, No. 2 (2013), pp. 143-174. 


\section{Maurice Finocchiaro}

exposure to Samuelson's textbook, such points can be easily retrieved from many sources; and conversely, noticing such points can serve as a clue for the general cultural importance of the problem of economic composition.

In Elements of Logic, Whately has a four-page discussion of the fallacies of composition and division, which would need to be examined carefully in a full treatment of this topic. Here I only wish to call attention to the fact that among his many more or less realistic examples, there are two that relate to economics: "the imprudent spendthrift, finding that he is able to afford this, or that, or the other expense, forgets that all of them together will ruin him" (Whately 1826, p. 176). The second example is one in which people sometimes skirt their responsibility by telling themselves that they are "not bound to contribute to this charity in particular; nor to that; nor to the other: the practical conclusion which they draw, is, that all charity may be dispensed with" (Whately 1826, p. 176).

The spendthrift example was later quoted by John S. Mill in his two-page discussion of the fallacy of composition in A System of Logic (1961, pp. 536-537). A similar example is given in what seems to be the only study of this fallacy published in the journal Informal Logic. The author (Pole 1981) regards the fallacy of composition as one of several kinds of fallacies involving the partwhole distinction, and he also discusses a special case of composition, which he labels the "salesman's fallacy." This presumably occurs when a salesman tries to sell us a product (e.g., an automobile or a house) which is really beyond our means, by focusing on each part or accessory and stressing the point that we can afford that particular accessory. The fallacy is presumably the argument that the whole automobile is affordable because each part is affordable.

It is also interesting that the 1976 unabridged edition of Webster's Third New International Dictionary saw it fit to give an example in its entry on the fallacy of composition, and it is an economic example: "if my money bought more goods I should be bet-

(c) Maurice Finocchiaro. Informal Logic, Vol. 33, No. 2 (2013), pp. 143-174. 
ter off; therefore, we should all benefit if prices were lower" (p. 818).

Let us now look at the considered reflective judgment of some economists, before we examine their examples. In the third edition of his famous textbook Economics, Samuelson (1955) has an introductory chapter in which one of several sections is entitled "the whole and the part: the "fallacy of composition'" (p. 9). In it, he starts by giving seven examples of paradoxical-sounding statements that are nevertheless true, such as: "1. If all farmers work hard and nature cooperates in producing a bumper crop, total farm income may fall. ... 6. Attempts of individuals to save more in depression may lessen the total of the community's savings" (Samuelson 1955, p. 9). He claims that these statements can be easily and clearly shown to be true, as he actually does at various points in the book, when the various particular topics come up for discussion. And then comes the connection with the present topic:

many of the above paradoxes hinge upon one single confusion or fallacy, called by logicians the 'fallacy of composition'. In books on logic, this is defined as follows: 'A fallacy in which what is true of a part is, on that account alone, alleged to be also true of the whole'. Very definitely, in the field of economics, it turns out that what seems to be true for each individual is not always true for society as a whole. (Samuelson 1955, p. 10)

By way of general introduction, it should also be noted that the term "fallacy of composition" is duly listed in the book's index, and that it is the only fallacy listed there. That index gives several references, including three to important examples not mentioned in the introduction: private debt vs. public debt, individual banks vs. the banking system, and the connection between commodity prices and land rents.

Such quotations from a distinguished economist are meant here primarily to help document the cultural ubiquity of the eco-

(C) Maurice Finocchiaro. Informal Logic, Vol. 33, No. 2 (2013), pp. 143-174. 


\section{Maurice Finocchiaro}

nomic fallacy of composition. I believe they provide some degree of support, even though there are two potentially damaging issues that cannot be ignored at this point.

First, let us call attention to the clause "on that account alone," in the definition which Samuelson adopts from logic books; it may be labeled the "exclusionary clause." He seems to be referring to arguments concluding that the whole has a certain property just because the parts have that property; this may be contrasted to saying partly because or primarily because. In other words, he is talking about compositional arguments whose only premises are claims that attribute a certain property to the parts, thus excluding other premises that might assert something about the relationship among the parts. And he is talking about arguments claiming more than that the truth of the premises makes the truth of the conclusion likely, and much more than that they provide some support to the conclusion. Samuelson's exclusionary clause does indeed increase the likelihood that the inference is erroneous, for as we saw in our discussion of Govier's account, it would exclude adding any gapbridging premises. At the same time, we should note that such exclusionary compositional arguments are not automatically or necessarily deductively invalid. In fact there are instances that are valid, such as the following variant of Copi's hackneyed example: since every part of this machine has weight (mass), the machine as a whole has weight (mass).

The second qualification involves the distinction between appearance and reality. Note that Samuelson says that in economics what seems to be true for each individual is not always true for the whole society. However, it is also the case that what seems to be true for each individual is not always really true of that individual. And when this happens, the main reason why the inference to the whole society does not hold may be that the individuals do not actually have the property in question in the first place, and so the compositional argument in question is not simply an instance of reasoning from parts to the whole, but has two steps: from apparent

(c) Maurice Finocchiaro. Informal Logic, Vol. 33, No. 2 (2013), pp. 143-174. 
properties of parts to actual properties of parts, and from the latter to actual properties of the whole; now, the weak point may be the first step of this chain inference rather than the second.

Let us now go on to a much later edition of Samuelson's textbook, the 13th of 1989, co-authored with his former student Nordhaus. By and large, there is slightly less emphasis on the fallacy of composition, and fewer and less frequent examples are discussed. Nevertheless, this fallacy is still referenced in the index; included in a new "Glossary" of terms; illustrated concretely in three different chapters; and discussed generally in a two-page section of the introductory chapter. In that general introduction, the fallacy is now presented as only one of several "pitfalls in economic reasoning," the others being the fallacy of post hoc, ergo propter $h o c$, and the failure to appreciate the qualification "other things being equal," to appreciate that observation and perception are theory-laden, and to appreciate that economic laws are statistical and not exact.

That introductory discussion begins with the following words:

Have you ever seen people jump up at a football game to gain a better view? They usually find that, once everybody is standing up, the view has not improved at all. Such behavior, where what is true for an individual is not necessarily true for everyone, illustrates the 'fallacy of composition', which is defined as follows: the fallacy of composition occurs when what is true of a part is therefore believed to be true for the whole. (Samuelson and Nordhaus 1989, pp. 7-8)

Then four brief examples are given, corresponding to some of those in the list of the 1955 edition. As we can see, the earlier exclusionary clause is gone from the general definition; gone is also the earlier tendency to confuse this issue with the issue of appearance vs. reality; and an incisive non-economic example is given, involving people viewing an athletic game in a stadium.

(c) Maurice Finocchiaro. Informal Logic, Vol. 33, No. 2 (2013), pp. 143-174. 


\section{Maurice Finocchiaro}

Another piece of evidence for the cultural ubiquity of the economic fallacy of composition is an internet essay entitled "Teaching the Fallacy of Composition: The Federal Budget Deficit," by L. Randall Wray, a professor of economics at the University of Missouri-Kansas City. This article appeared as the second item, at the top of a list of 1,130,000 items, found by a Google search of the "fallacy of composition" (consulted on October 19, 2012). Wray states that "one of the most important concepts taught in economics is the notion of the fallacy of composition: what might be true for individuals is probably not true for society as a whole." Then he gives three brief examples overlapping with Samuelson's list: the paradox of thrift; the causes (individual vs. social) of unemployment; and the effects (micro vs. macro) of a minimumwage law. And then he elaborates a great length the all-important example of public vs. private debt.

The only thing to note at the moment is that Wray's definition explicitly injects the notion of probability into the inference from parts to whole. This is an improvement, for the probability clause makes it clear that compositional arguments are normally meant to be inductive and defeasible, not deductive.

To conclude this section, although the story does not end here either, it would seem rash or injudicious to dismiss such economists' talk of the fallacy of composition. In the domain of economic affairs and thinking, the fallacy of composition seems to have some reality and robustness, above and beyond the trivial and hackneyed examples of logic textbooks.

\section{The fallacy of composition as an error of oversimplification}

One of the internet comments on Wray's essay is also culturally important. Moreover, it raises a relatively novel issue, which is potentially significant from the point of view of logic and argumentation theory. It is one of twenty-nine comments and was posted on

(C) Maurice Finocchiaro. Informal Logic, Vol. 33, No. 2 (2013), pp. 143-174. 
August 23, 2009 by an anonymous respondent, who used the label "Razorback." The most relevant claim is this: "read a classic from Hazlitt, Economics in One Lesson. It deals (extensively) with the pervasive logical 'fallacy of composition', which basically is a tendency of most thinkers to oversimplify the 'micro' effects and then perform a simple sigma summation to derive the 'macro' and then apply further reasoning from there."

(http://neweconomicperspectives.org/2009/08/teaching-fallacy-ofcomposition-federal.html; consulted on October 19, 2012).

This respondent is referring to a book which was first published in 1946; became a best seller; and had a second edition in 1979. The author is Henry Hazlitt, a libertarian economist (and philosopher) belonging to the "Austrian school" of economics. In this book, Hazlitt's main thesis is that

the whole of economics can be reduced to a single lesson, and that lesson can be reduced to a single sentence. The art of economics consists in looking not merely at the immediate but at the longer effects of any act or policy; it consists in tracing the consequences of that policy not merely for one group but for all groups. (1979, p. 17)

Hazlitt also has a negative way of expressing this key point: "economics is haunted by more fallacies than any other study known to man" (1979, p. 15); and "nine-tenths of the economic fallacies that are working such dreadful harm in the world today are the result of ignoring this lesson. Those fallacies all stem from one of the two central fallacies, or both: that of looking only at the immediate consequences of an act or proposal, and that of looking at the consequences only from a particular group to the neglect of other groups" (p. 17).

The most immediate thing to note here is that, insofar as Hazlitt is dealing with the fallacy of composition, his work adds another dimension to its cultural ubiquity. This stems from the fact that he may be regarded as an important representative of conservative

(c) Maurice Finocchiaro. Informal Logic, Vol. 33, No. 2 (2013), pp. 143-174. 


\section{Maurice Finocchiaro}

or right-wing thinking, just as Samuelson may be regarded as a leading exponent of liberal or left-wing thinking. To that extent, the exposure of the fallacy of composition seems to be a concern common to both sides of the political and ideological spectrum, and so it is not merely an ideological tool of one side against the other.

However, let us ask whether Hazlitt is really talking about this fallacy. In fact, he does not explicitly use the term "fallacy of composition." Thus, if we want to attribute the concept to him, as the anonymous respondent to Wray does, then we need to interpret the fallacy or fallacies described but not named by Hazlitt as either a generalization or a special case of composition. And this may be what the anonymous respondent is suggesting.

To address this issue, let us begin by noting that the anonymous respondent is not just reiterating the usual definition of the fallacy of composition, but is rather giving an interesting interpretation of it, which I would in turn interpret as follows. He is focusing on arguments that try to derive macro effects from micro ones, which correspond to what I have called compositional arguments. And he is claiming that such arguments are often erroneous, insofar as they embody an oversimplification that does not properly take into account various complications, but instead simply generalizes the properties of the micro phenomena to the macro level. Such erroneous compositional arguments are fallacies of composition.

Next, let us note that Hazlitt is concerned, first and foremost, to contrast short-term with long-term consequences, and the effects on a single particular group with the effects on the aggregate of all groups, i.e., on the whole society. Now, both of these contrasts may be seen as special cases of the distinction between the micro and the macro level, which almost everyone writing on this topic makes. With the first contrast, Hazlitt is extending the micro vs. macro distinction to the temporal domain, by viewing the short term as a micro period of time, and the long term as a macro period. With the second contrast, Hazlitt is extending the parts vs.

(C) Maurice Finocchiaro. Informal Logic, Vol. 33, No. 2 (2013), pp. 143-174. 
whole distinction by focusing on parts of a whole society that are themselves aggregates of individuals, rather than just on individuals. Both extensions seem plausible. Thus, Hazlitt is really dealing with the compositional phenomenon, compositional attributes, and compositional arguments, after all.

In his negative, critical thesis, Hazlitt is concerned with exposing the error of over-emphasizing the parts or micro phenomena and understating the whole or macro phenomena. One such typical error would be to start with what is known about the micro or parts, and then argue that the exact same thing is true about the macro level of the whole. Such argumentation runs the risks of which the anonymous respondent speaks: an oversimplification of the description of the micro phenomena, and/or an oversimplification of the way in which they are added up or combined to yield the macro phenomena. Thus, what is usually called the fallacy of composition becomes a special case of the error of oversimplification. (Whether we should speak of the fallacy of oversimplification, I leave it as an open question at the moment.) In short, the anonymous respondent seems to have a point in claiming that the key concern of Hazlitt's book is to expose the fallacy of composition in economic thinking, even though Hazlitt does not use the usual label and is generalizing the usual distinction of micro vs. macro.

On the other hand, it may not be an accident that Hazlitt does not speak of the fallacy of composition. Perhaps he is really concerned with exposing the error of oversimplification in economic affairs, committed through the neglect of considerations of the long run (as contrasted to the short run) and/or of the whole society (as contrasted to a part), and through the neglect of complexities in combining the micro to yield the macro. Here the key issue would seem to be the avoidance of one-sidedness and of extremes; that is, judiciousness or balanced judgment, in my terminology introduced above. It is not at all obvious that there is any advantage in speaking of the fallacy of composition rather than speaking of oversimplification and injudiciousness. If there is no such advantage, then

(c) Maurice Finocchiaro. Informal Logic, Vol. 33, No. 2 (2013), pp. 143-174. 


\section{Maurice Finocchiaro}

Hazlitt's work cannot be used to strengthen the case for the cultural ubiquity of the economic fallacy of composition.

More importantly, from the point of view of logic and argumentation theory, perhaps fallacies of composition are basically errors of oversimplification. If so, this would provide another reason why the concept of fallacy of composition is problematical: for this would amount to saying that (at best) fallacies of composition are not a distinctive kind of error, since they would be special cases of the error of oversimplification, and the concept of oversimplification is neither simple nor unified but rather subsumes a multiplicity of oversights. This reason may be added to the one that earlier I extracted from Govier's account, namely that fallacies of composition are not a distinct kind of argument, because compositional arguments do not constitute a natural or distinctive kind. Putting the two together, we get that fallacies of composition are neither a distinctive kind of argument nor a distinctive kind of error. What are they, then? They are instances of compositional arguments that oversimplify the relationship between the micro and macro levels, the parts and the whole, the individual and society.

\section{Further testing and extended examples}

These deconstructionist ${ }^{11}$ claims about the fallacy of composition need further testing. Although this testing cannot be undertaken in this essay, here it will be useful to sketch and summarize the material and the extended examples I have in mind for this purpose.

\footnotetext{
${ }^{11}$ Needless to say, my talk of deconstruction is not meant to have the technical meaning stemming from the philosophy of Jacques Derrida and related systems of thought. Rather it is meant to have the ordinary meaning of this term, which is "the analytic examination of something (as a theory) often in order to reveal its inadequacy" (Merriam-Webster Dictionary online, available at http://www.merriam-webster.com/dictionary/deconstruction (consulted on 15 February 2013).
}

(C) Maurice Finocchiaro. Informal Logic, Vol. 33, No. 2 (2013), pp. 143-174. 
One next step would be to undertake a detailed, concrete, and substantive examination of what I regard as the best examples of economic fallacies of composition that can be gleaned from Samuelson's and Wray's works mentioned above. One of these examples involves the topic of private or personal vs. public or national debt, and the question whether it is fallacious to argue that a constant or excessive national debt is irresponsible or ruinous just because (or primarily because, or partly because) a constant or excessive personal debt is irresponsible or ruinous (Samuelson 1955, pp. 350352; Samuelson and Nordhaus 1989, pp. 399-404; Wray 2009, pp. 2-5). Another paradigm example concerns the phenomenon that the whole banking system can expand the money supply even though a single bank cannot, and the fallaciousness of arguing that since no single bank by itself can create money, neither can the banking system as a whole do so (Samuelson 1955, pp. 273-278). The third important example deals with the relationship between commodity prices and land rents: at the level of an individual entrepreneur or firm, land rents contribute to determining commodity prices, whereas, at the macro level of the whole economy, the reverse happens (commodity prices contribute to determining land rents); here the fallacy of composition would be to argue that since at the micro level the direction of causation is from rents to prices, therefore at the macro level the direction is also from rents to prices (Samuelson 1955, pp. 504-505; Samuelson and Nordhaus 1989, pp. 667-668).

A second project would search for compositional arguments and fallacies of composition in political science. In particular, there happens to be some material which is highly relevant, and involves one of the most famous and widely-discussed principles in that field - the so-called "iron law of oligarchy": that every bureaucratic organization has oligarchical tendencies which are impossible to overcome, and that this applies even to democratic institutions, which are thus doomed to become undemocratic. This law was advanced in a book by Robert Michels, first published in German in

(c) Maurice Finocchiaro. Informal Logic, Vol. 33, No. 2 (2013), pp. 143-174. 


\section{Maurice Finocchiaro}

1911, and in English in 1962, revealigly entitled Political Parties: A Sociological Study of the Oligarchical Tendencies of Modern Parties.

Now, some of the most distinguished social scientists of the twentieth century have criticized Michels's argument in support of the law by charging him with errors that are clearly reminiscent of the fallacy of composition, even though these critics do not use this label. One of these critics is Robert Dahl, the founder of a field known as democratic theory (Dahl 1956; 1989). Dahl charges that Michels begins by studying the workings of political parties, in particular the German Social Democratic Party; he discovers that even parties advocating democracy have insurmountable oligarchical (anti-democratic) tendencies; he concludes that what is true of political parties is also true of governmental institutions or societies as a whole; and thus he commits an error of reasoning, consisting of illegitimately generalizing from parts to the whole (Dahl 1989, pp. 275-277). Another important criticism is advanced by Seymour Martin Lipset, a political sociologist who wrote the introduction to the English translation of Michels's book. Lipset's key charge is that Michels failed to appreciate that a whole society can be democratic (anti-oligarchical) even though it is composed of parts that are oligarchical (anti-democratic); this happens when there exist institutions that prevent any one group from exercising despotic power over opposing groups (Lipset 1962, pp. 36-37).

A third project would be to attempt to relate the controversy of holism vs. individualism in sociology to the fallacy of composition, that is, to interpret that controversy in argumentationtheoretical terms in general, and compositional arguments in particular. In fact, at the descriptive or semantic level, individualism affirms, and holism denies, that all properties of the whole can be defined in terms of properties of the parts; whereas at the explanatory or epistemic level, individualism affirms, and holism denies, that all properties or laws at the macro or social level are in principle derivable from, explicable by, or reducible to the properties or

(C) Maurice Finocchiaro. Informal Logic, Vol. 33, No. 2 (2013), pp. 143-174. 
laws at the micro or individual level (cf. Addis 1999, Jones 2003). Thus, individualism would seem to correspond to the claim that compositional arguments can in principle be correct; whereas holism would correspond to the thesis that some compositional argument must be fallacious.

\section{Epilogue}

I began with a critical appreciation of Govier's account of the fallacy of composition. I endorsed her approach insofar as it typically displays balanced judgment (by avoiding one-sidedness and extremes), and insofar as it embodies a sound realism (by focusing on important actual or realistic examples). And I found acceptable some of her substantive claims: that compositional attributions are problematic; and that compositional arguments exemplify a variety of argument kinds, such as deductive, analogical, and generalization. However, I questioned her notion of the fallacy of composition, by arguing that she has a tendency to hypostatize the concept; that is, she wavers between the notion of a compositional argument (that can be correct or incorrect) and the notion of the fallacy of composition (as a mistaken argument of composition), thus depriving her account of genuine evaluative value; and she fails to see that the multiplicity of argument kinds subsumed under the notion of fallacy of composition deprive it of interpretive significance.

Then I undertook a critical appreciation of the topic of the fallacy of composition in economic thinking and in the writings of some economists. The first positive point was that there is considerable prima facie evidence that the economic fallacy of composition is ubiquitous in our culture; although this is apparently unknown or little discussed among philosophers, the exposure of such a fallacy is a constant refrain among economists on both the right and left wings of the political spectrum. A second positive point was the claim that the essential flaw of economic fallacies of com-

(c) Maurice Finocchiaro. Informal Logic, Vol. 33, No. 2 (2013), pp. 143-174. 


\section{Maurice Finocchiaro}

position is an error of oversimplification in dealing with inferences from the micro to the macro level; I extracted this thesis from some of these writings. On a critical note, from the point of view of logic and argumentation theory, insofar as fallacies of composition are essentially errors of oversimplification, they do not constitute a distinctive kind of error.

Finally, I proposed some further testing of my "deconstructionist" claim that the so-called fallacy of composition is neither a distinctive kind of argument nor a distinctive type of error. The tests involve concrete and important examples of alleged fallacies of composition from the social sciences. In economics, there is the all-important issue of public vs. private debt, as well as the question of effects on the money supply of a particular bank and of the whole banking system, and the problem of the micro-level vs. macro-level direction of causation between commodity prices and land rents. In political science, we have the issue of whether, and if so how, a whole society can be democratic even when it consists of particular institutions that tend to be oligarchic or anti-democratic. And in sociology the issue of holism vs. individualism provides examples of compositional arguments that may or may not be fallacies of composition.

\section{References}

Addis, L. (1999). Holism. In R. Audi (Ed.), Cambridge Dictionary of Philosophy, $2^{\text {nd }}$ ed. (pp. 390-91). New York: Cambridge University Press.

Arnauld, A., and Nicole, P. (1996). Logic or the Art of Thinking. Trans. J.V. Buroker. Cambridge: Cambridge University Press.

Barth, E.M., J. Vandormael, and F. Vandamme (Eds.). (1992). From an Empirical Point of View: The Empirical Turn in Logic. Ghent: Communication and Cognition. 
Deconstructing the Fallacy of Composition 171

Copi, I.M. (1968). Introduction to Logic, $3^{\text {rd }}$ ed. New York: MacMillan.

Dahl, R.A. (1956). A Preface to Democratic Theory. Chicago: University of Chicago Press.

Dahl, R.A. (1989). Democracy and Its Critics. New Haven: Yale University Press.

Finocchiaro, M.A. (1980). Galileo and the Art of Reasoning: Rhetorical Foundations of Logic and Scientific Method. (Boston Studies in the Philosophy of Science, vol. 61.) Dordrecht: Reidel [now Springer].

Finocchiaro, M.A. (1981). Fallacies and the evaluation of reasoning. American Philosophical Quarterly 18, 13-22. Reprinted in Finocchiaro 2005, pp. 109-27.

Finocchiaro, M.A. (1987). Six types of fallaciousness: Toward a realistic theory of logical criticism. Argumentation 1, 263-82. Reprinted in Finocchiaro 2005, pp. 128-47.

Finocchiaro, M.A. (1988). Gramsci and the History of Dialectical Thought. Cambridge: Cambridge University Press.

Finocchiaro, M.A. (2005). Arguments about Arguments: Systematic, Critical, and Historical essays in Logical Theory. New York: Cambridge University Press.

Finocchiaro, M.A. (2010). Defending Copernicus and Galileo: Critical Reasoning in the Two Affairs. (Boston Studies in the Philosophy of Science, vol. 280.) Dordrecht: Springer.

Finocchiaro, M.A. (2013). Meta-argumentation: An Approach to Logic and Argumentation Theory. (Studies in Logic, vol. 42.) London: College Publications.

Fisher, A. (2004). The Logic of Real Arguments, $2^{\text {nd }}$ ed. Cambridge: Cambridge University Press.

Govier, T. (1982). Who says there are no fallacies? Informal Logic Newsletter 5(1), 2-10.

Govier, T. (1987). Problems in Argument Analysis and Evaluation. Dordrecht: Foris.

(C) Maurice Finocchiaro. Informal Logic, Vol. 33, No. 2 (2013), pp. 143-174. 


\section{Maurice Finocchiaro}

Govier, T. (1995). Reply to Massey. In: H.V. Hansen and R.C. Pinto (Eds.), Fallacies: Classical and Contemporary Readings (pp. 172-180). University Park, PA: The Pennsylvania State University Press.

Govier, T. (1999). The Philosophy of Argument. Newport News, VA: Vale Press.

Govier, T. (2000). Critical review: Johnson's Manifest Rationality. Informal Logic 20, 281-91.

Govier, T. (2007). Duets, cartoons, and tragedies: Struggles with the fallacy of composition. In F.H. van Eemeren, J.A. Blair, C.A. Willard, and B. Garssen (Eds.), Proceedings of the Sixth Conference of the International Society for the Study of Argumentation (pp. 505-11). Amsterdam: Sic Sat.

Govier, T. (2009). Duets, cartoons, and tragedies: Struggles with the fallacy of composition. In F.H. van Eemeren and B. Garssen (Eds.), Pondering on Problems of Argumentation (pp. 91-104). Dordrecht: Springer.

Govier, T. (2010). A Practical Study of Argument, $7^{\text {th }}$ ed. Belmont,CA: Wadsworth.

Hansen, H.H. (2002). The straw thing of fallacy theory: The standard definition of 'fallacy'. Argumentation 16, 133-55.

Hazlitt, H. (1979). Economics in One Lesson. New Rochelle: Arlington House Publishers. 1st edn., 1946.

Johnson, R.H. (2000). Manifest Rationality: A Pragmatic Theory of Argument. Mahwah: Lawrence Erlbaum Associates.

Jones, T. (2003). The failure of the best arguments against social reduction (and what that failure doesn't mean). Southern Journal of Philosophy 41, 547-81.

Jones, T. (2010). What People Believe when They Say That People Believe: Folk Sociology and the Nature of Group Intentions. Lanham, MD: Lexington Books.

Lipset, S.M. (1962). Introduction to Michels 1962, pp. 15-39.

(C) Maurice Finocchiaro. Informal Logic, Vol. 33, No. 2 (2013), pp. 143-174. 
Michels, R. (1962). Political Parties: A Sociological Study of the Oligarchical Tendencies of Modern Parties. Trans. E. Paul and C. Paul. New York: Collier.

Mill, J.S. (1961). A System of Logic: Ratiocinative and Inductive. London: Spottiswoode. $1^{\text {st }}$ ed., London: Longmans, 1843.

Nelson, A. (1999). Keynes. In R. Audi (Ed.), Cambridge Dictionary of Philosophy, $2^{\text {nd }}$ ed. (pp. 467-68). New York: Cambridge University Press.

Pole, N. (1981). Part/whole fallacies. Informal Logic Newsletter 3(3), pp. 11-13.

Samuelson, P.A. (1955). Economics: An Introductory Analysis, $3^{\text {rd }}$ ed. New York: McGraw-Hill.

Samuelson, P.A., and W.D. Nordhaus (1989). Economics, $13^{\text {th }}$ ed. New York: McGraw-Hill.

Walton, D. (2010). Why fallacies appear to be better arguments than they are. Informal Logic 30, 159-84.

Walton, D., C. Reed, and F. Maccagno (2008). Argumentation Schemes. Cambridge: Cambridge University Press.

Whately, R. (1826). Elements of Logic. London: J. Mawman. Rpt., Bologna, Italy: Editrice CLUEB, 1988

Woods, J. (1988). Buttercups, GNP's, and quarks: Are fallacies theoretical entities? Informal Logic 10, 67-76. Reprinted in Woods 2004, pp. 161-70.

Woods, J. (2004). The Death of Argument: Fallacies in AgentBased Reasoning. Dordrecht: Kluwer.

Woods, J. (2012). A history of the fallacies in Western logic. In D.M. Gabbay, F.J. Pelletier, and J. Woods (Eds.), Logic: A History of Its Central Concepts (pp. 513-610). Amsterdam: NorthHolland.

Woods, J. (2013). Errors of Reasoning: Naturalizing the Logic of Inference. (Studies in Logic, vol. --.) London: College Publications.

(C) Maurice Finocchiaro. Informal Logic, Vol. 33, No. 2 (2013), pp. 143-174. 


\section{Maurice Finocchiaro}

Woods, J., and D.N. Walton (1977a). Composition and division. Studia Logica 36, 381-406. Reprinted in Woods and Walton 1989, pp. 93-119.

Woods, J., and D.N. Walton (1977b). Post hoc, ergo propter hoc. Review of Metaphysics 30, 569-93. Reprinted in Woods and Walton 1989, pp. 121-41.

Woods, J., and D.N. Walton (1989). Fallacies: Selected Papers 1972-1982. Dordrecht: Foris Publications.

Wray, L.R. (2009). Teaching the fallacy of composition: The federal budget deficit. At the website:

http://neweconomicperspectives.org/2009/08/teaching-fallacyof-composition-federal.html. Consulted on October 19, 2012.

(C) Maurice Finocchiaro. Informal Logic, Vol. 33, No. 2 (2013), pp. 143-174. 